Check for updates

Cite this: J. Mater. Chem. A, 2020, 8 , 3933

Received 11th November 2019 Accepted 15th January 2020

DOI: $10.1039 / c 9 t a 12396 b$

rsc.li/materials-a

\section{Hydrogen/functionalized benzoquinone for a high- performance regenerative fuel cell as a potential large-scale energy storage platform $\dagger$}

\author{
Javier Rubio-Garcia, ${ }^{a}$ Anthony Kucernak, (ID *a Andres Parra-Puerto, ${ }^{\text {a }}$ Rutao Liu ${ }^{a}$ \\ and Barun Chakrabarti it $^{\mathrm{b}}$
}

\begin{abstract}
The redox flow battery (RFB) is a suitable option for electricity storage due to its high energy efficiency, scalability and relative safety. However, the limited metallic resources for redox materials and the high cost of systems such as the all-vanadium RFB are major challenges for its wider application. Organics may be sourced more abundantly and have lower prices than metal based redox couples. In this work a regenerative fuel cell involving relatively inexpensive organic redox couples is demonstrated. The electrochemical properties of 1,2-dihydrobenzoquinone-3,5-disulfonic acid (BQDS) are characterised by cyclic voltammetry and linear-sweep voltammetry under hydrodynamic conditions. A regenerative fuel cell using $0.65 \mathrm{M} \mathrm{BQDS}$ in $1 \mathrm{M} \mathrm{H}_{2} \mathrm{SO}_{4}$ as the positive electrolyte and gaseous hydrogen ( 1 bar) as the negative redox-material exhibits an open circuit cell voltage of $0.86 \mathrm{~V}$, a power density of $122 \mathrm{~mW} \mathrm{~cm}$, and an energy density of $10.90 \mathrm{~W} \mathrm{~h} \mathrm{~L}^{-1}$ without considering the volume occupied by the hydrogen. $\mathrm{A}$ very promising performance with an energy efficiency $>60 \%$ at $100 \mathrm{~mA} \mathrm{~cm}{ }^{-2}$ for 200 cycles is reported. New organic redox species resistant to side reactions could facilitate the use of this new system in practical applications. The use of hydrogen may also contribute to reduced side reactions of the organic redox material associated with degradation in the presence of oxygen.
\end{abstract}

\section{A Introduction}

Since the concept was first presented by NASA in the 1970s, redox flow batteries (RFBs) have attracted attention because they have the potential to meet the requirements of durability for repeated charge/discharge, rapid response to changes in load or input and have a high capacity retention, a high roundtrip efficiency and reasonable capital costs. ${ }^{1}$ RFBs offer attractive features for application on the medium to large scale including high system capacity, longevity and reasonable cost per $\mathrm{kW} \mathrm{h} .^{2-5} \mathrm{~A}$ typical RFB has two electrolyte reservoirs storing chemical energy, the positive and negative electrolyte reservoirs. Each electrolyte is pumped into the flow cell, which is built with two electrodes and an ion exchange membrane. As a consequence of the external reservoir design, the capacity of the RFB can be scaled up easily and independently of power output (which is dependent on cell stack dimensions) by increasing the size of the reservoirs to store more redox material. ${ }^{1,6,7}$

\footnotetext{
${ }^{a}$ Department of Chemistry, Imperial College London, SW7 2AZ, UK. E-mail: anthony@ imperial.ac.uk

${ }^{b} R F C$ Power, 52 Princes Gate, Exhibition Road, London, SW7 2PG, UK

$\dagger$ Electronic supplementary information (ESI) available: ${ }^{1} \mathrm{H}$ NMR results and discussion. See DOI: 10.1039/c9ta12396b

‡ Current address: WMG, Electrochemical Engineering Group, Energy Innovation Centre, University of Warwick, Coventry, CV5 7AL, UK.
}

Various metal-based redox couples have been applied to RFB applications, with the vanadium redox couple achieving commercial deployment. ${ }^{6,8-10}$ The all vanadium $\mathrm{RFB}$ uses $\mathrm{VO}^{2+} /$ $\mathrm{VO}_{2}{ }^{+}$as the redox material in the positive electrolyte reservoir and $\mathrm{V}^{2+} / \mathrm{V}^{3+}$ in the negative electrolyte reservoir, producing a cell voltage of $1.26 \mathrm{~V}$ and is able to operate for more than 10000 deep discharge cycles at relevant round trip efficiencies. ${ }^{11-14}$ However, vanadium is a rare element so the capital cost of the redox material is a big obstacle for the large-scale commercialisation of the VRFB. ${ }^{15-19}$ The energy cost of a VRFB is $\$ 320$ per $\mathrm{kW} h$ whilst the target set by the U.S. Department of Energy (DOE) is $\$ 100$ per $\mathrm{kW} \mathrm{h}$, with almost $50 \%$ of the price being dominated by the cost of the electrolyte..$^{20,21}$

In response to the price sensitivity of vanadium, various redox-active species have been investigated and suitable ones tailored to lower the cost of RFB redox materials. From 2009 onwards, when an RFB utilising organic chloranil redox material was demonstrated, ${ }^{22}$ the implementation of organic redox active species has been explored owing to their ubiquity in nature and more economical price than their metal-based redox counterparts. ${ }^{23}$ In general, organic active species offer multiple molecular configurations by functionalization with electrondonating or withdrawing groups which enable tunability of the redox behaviour and solubility ${ }^{24-26}$ The most investigated redox active organic materials include metallocenes using ubiquitous metals such as iron, ${ }^{27,28}$ quinones, ${ }^{29,30}$ nitroxide 
radicals, ${ }^{31,32}$ and viologens. ${ }^{26}$ In this context, researchers at Harvard have pioneered the exploration of anthraquinone moieties which resulted in promising electrochemical activity at both low and high $\mathrm{pH}^{23,33}$ For instance, in their quinonebromide flow battery system, the workers functionalised the anthraquinone backbone with sulphonate groups (AQDS) to ensure better solubility at low $\mathrm{pH} .{ }^{23}$ In a separate investigation, ether-linked alkyl chains with solubilizing carboxylate functional groups were added onto an anthraquinone core to enable high chemical stability and high solubility $(0.6 \mathrm{M}$ at $\mathrm{pH} 12$; 1.1 $\mathrm{M}$ at $\mathrm{pH}$ 14) in alkaline electrolytes. ${ }^{34}$ However, selfdimerization of AQDS at high concentrations was reported subsequently for bisulphonated quinones. ${ }^{35}$ The dimerization prevents the full-oxidation of the molecule, which means there will be unstable redox-active species in highly concentrated electrolytes. ${ }^{36}$ Self-discharge mechanisms were briefly presented but not discussed as a function of operating time; the authors showed cell discharge at different current densities as a function of cycle number, which may not have revealed full capacity fading issues. In this context, many organic redox couples and particularly hydro-quinones (and hydro-anthraquinones) are known for their sensitivity towards molecular oxygen to regenerate the corresponding quinone with concomitant production of hydrogen peroxide. While this reactivity has been industrially exploited in the synthesis of hydrogen peroxide, ${ }^{37,38}$ the mechanism would lead to self-discharge if oxygen is present in the RFB electrolyte reservoir, and the presence of hydrogen peroxide could lead to deleterious reactions leading to destruction of the redox couples.

As a consequence of these observations, Prakash et al. reported a full-organic RFB (ORFB) system with the water-soluble 1,2-dihydrobenzoquinone-3,5-disulfonic acid (BQDS) on the positive side and anthraquinone-2,6-disulfonic acid (AQDS) on the negative side. ${ }^{39,40}$ The cell was able to operate at $100 \mathrm{~mA}$ $\mathrm{cm}^{-2}$ for more than 100 cycles with $100 \%$ current efficiency, which proved that the redox-active quinone-based molecules have a high chemical reversibility. However, the presence of different aqueous-based redox couples in both half-cells can cause long term capacity fading issues due to active species crossover through the ion-exchange membrane leading to irreversible degradation of the RFB.

A regenerative fuel cell (RFC) architecture enables a decrease of the electrolyte cost and minimises irreversible RFB degradation due to control of crossover of active species. In this regard, the most common example of crossover problems in an RFC is from the highly investigated hydrogen/bromine system, which is associated with platinum catalyst poisoning and corrosion due to constant contact with a bromine containing liquid that infiltrates through the membrane towards the hydrogen/proton half-cell. ${ }^{\mathbf{4 1 - 4 3}}$ Furthermore, bromine is toxic and can cause corrosion particularly at the noble metal hydrogen catalyst. In contrast, the regenerative hydrogen/ vanadium fuel cell (RHVFC) system utilises gaseous hydrogen and a vanadium liquid electrolyte as the redox materials. ${ }^{\mathbf{4 4}}$ This design not only lowers the capital cost of the RFB, but also reduces the self-discharge caused by electrolyte crosscontamination as any electrolyte reaching the gas side can be easily collected and pumped back to the positive electrolyte reservoir. ${ }^{45}$ The hydrogen reaction catalysed by platinum has very fast kinetics, which is not affected by vanadium crossover as it is by $\mathrm{Br}$ in the $\mathrm{H}_{2} / \mathrm{Br}_{2}$ system. An even more economical RFC is the recently reported hydrogen/manganese system $\left(\mathrm{H}_{2} /\right.$ $\mathrm{Mn}$ ), with a lower crossover rate than either vanadium or bromine, and even if there is crossover the manganese is inert to the Pt catalyst. ${ }^{15}$ As a consequence, both the RHVFC and $\mathrm{H}_{2}$ / Mn FC exhibit better durability than the $\mathrm{H}_{2} / \mathrm{Br}_{2}$ RFC. ${ }^{\mathbf{4 4 , 4 5}}$

The first hydrogen/benzoquinone $\left(\mathrm{H}_{2} / \mathrm{BQ}\right)$ system was reported by Harvard researchers with a reasonable power density of $35 \mathrm{~mW} \mathrm{~cm}^{-2}$ but cycling durability was not investigated. ${ }^{\mathbf{4 6}}$ More recently, Dargily and co-workers studied the performance of the same system and reported about 200 charge/discharge cycles. ${ }^{47}$ The poor solubility of the active species owing to non-functionalised $\mathrm{BQ}$ molecules restricted the operational current density $\left(20 \mathrm{~mA} \mathrm{~cm}{ }^{-2}\right)$, which meant that further practical studies were not feasible. In contrast, here we demonstrate how the utilization of a functionalised benzoquinone using disulfonic acid (BQDS) enables a low-cost system with an ability to operate at a relatively high current density $\left(100 \mathrm{~mA} \mathrm{~cm}^{-2}\right)$ whilst ensuring high efficiency. According to an independent study, ${ }^{\mathbf{4 0}}$ the specific capacity for such modified quinone molecules can range from 200 to $500 \mathrm{~A} \mathrm{~h} \mathrm{~kg}^{-1}$ whereas their cost can range anywhere from $\$ 10-15 \mathrm{~kg}^{-1}$ or $\$ 20-30 \mathrm{~kW} \mathrm{~h}^{-1}$, which has the potential of resulting in a much lower capital cost than the $\$ 400$ $\mathrm{kW} \mathrm{h}{ }^{-1}$ reported for $\mathrm{H}_{2} / \mathrm{Br}_{2}$ RFCs in the literature. ${ }^{48}$ In the authors' own words, "the demonstration of rechargeability and cycling of an ORFB using solely aqueous solutions of quinone derivatives on both sides of the cell (BQDS as the positive electrolyte) opened a new door to realizing an inexpensive, safe, and robust electrochemical system for large-scale energy storage". ${ }^{40}$

As shown in Scheme 1, during discharge of the $\mathrm{H}_{2} / \mathrm{BQDS}$ RFC, reduction of BQDS to 1,2-dihydroxybenzene-3,5-disulfonic acid occurs in the catholyte whilst during the charging process the oxidation of the latter species will take place forming BQDS. This RFC system avoids self-discharge from electrolyte crossover and achieves higher energy density because of hydrogen's compressible nature.

The use of hydrogen also potentially provides a reducing and blanketing atmosphere to store the catholyte in, reducing the likelihood of reaction with oxygen which would lead to a potential battery self-discharge pathway. In consideration of the primary development state of the ORFB system, the target cell performance is also based on the VRFB system. ${ }^{\mathbf{1 6}}$ Further optimisation of cell performance is expected to achieve values comparable with those of the commercialized VRFB which has an operational cell voltage of $1.26 \mathrm{~V}, 20-35 \mathrm{~W} \mathrm{~h} \mathrm{~L}^{-1}$ energy density, 75\% energy efficiency and more than 10000 cycles of durability under deep discharge. ${ }^{49}$

In this investigation, we report the coupling of the BQDS positive electrolyte as reported in the literature with the hydrogen system following our investigations on the RHVFC and $\mathrm{Mn} / \mathrm{H}_{2}$ RFCs. $^{15,16}$ The objective of this study is to determine practical operating conditions for not only achieving decent power densities for the $\mathrm{H}_{2}$ /BQDS system but also determining the system's cycling capabilities at a range of current densities. 


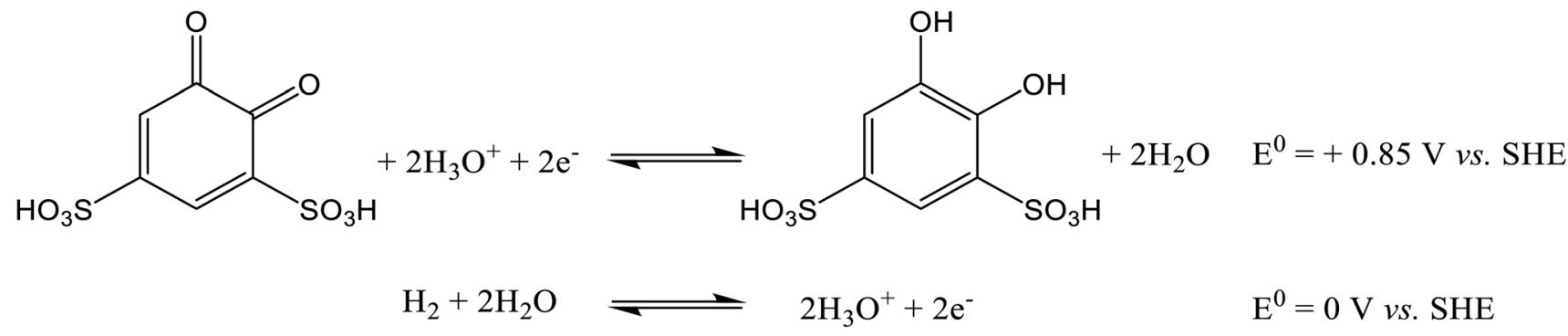

Scheme 1 Redox reactions occurring within the RFC.

We perform standard physicochemical and electrochemical studies to provide a new understanding of the redox reactions of BQDS and how the RFC performance is affected by this. We employ a standard membrane-electrode assembly to determine how the system will operate under non-optimised conditions in order to compare with more established RFBs such that a means for optimising performance can be established by other workers in an attempt to achieve commercial outreach in a similar, if not better, manner to VRFBs.

\section{B Experimental}

All experiments were performed at room temperature and pressure unless specified. The fuel cell fixture, which was purchased from Scribner Associates, consisted of two POCO graphite bipolar plates with a machined serpentine flow field in contact with gold-plated copper current collectors that are held together utilizing anodized aluminium end plates as detailed in a separate study. ${ }^{44}$ Commercially available $4.6 \mathrm{~mm}$ thick graphite felt (SGL group, Germany, Sigracell) was used as the positive electrode with an active geometric surface area of 5 $\mathrm{cm}^{2}$. The hydrogen negative electrode (of the same geometric surface area of $5 \mathrm{~cm}^{2}$ ) was obtained from Johnson Matthey Alfa Aesar ( $0.22 \mathrm{~mm}$ thickness with $0.4 \mathrm{mg}$ Pt per $\mathrm{cm}^{2}$ loading). Both electrodes were used as-received without any pretreatment. The membrane was Nafion ${ }^{\circledR} 117$ (nominal thickness $183 \mu \mathrm{m}$ ). To remove any contaminants in the membrane, the Nafion was activated via the following process: (1) it was immersed in de-ionized water at $80{ }^{\circ} \mathrm{C}$ for $1 \mathrm{~h}$; (2) then it was exposed to $30 \% \mathrm{H}_{2} \mathrm{O}_{2}$ at $80{ }^{\circ} \mathrm{C}$ for $1 \mathrm{~h}$; (3) this was followed by an immersion in $85 \% \mathrm{H}_{2} \mathrm{SO}_{4}$ at $80^{\circ} \mathrm{C}$ for $1 \mathrm{~h}$; and (4) finally the first step was repeated by heating the membrane in deionized water at $80{ }^{\circ} \mathrm{C}$ for $1 \mathrm{~h}$.

A peristaltic pump (Masterflex Easy-Load, Cole-Parmer) and Masterflex platinum-cured silicone tubing (L/S 14, $25 \mathrm{ft}$ ) were used to pump the liquid electrolyte through the cell at flow rates of $25-100 \mathrm{~mL} \mathrm{~min}{ }^{-1}$. Hydrogen (99.999\%, Air Products) was humidified and controlled (850e, Scribner Associates) before passing through the negative side of the cell at a flow rate of 25$100 \mathrm{~mL} \mathrm{~min}^{-1}$. Galvanostatic charge and discharge experiments were conducted using a Gamry potentiostat 3000 . The electrolyte was prepared by dissolving $0.65 \mathrm{M}$ 4,5-dihydroxy-1,3benzenedisulfonic acid disodium salt monohydrate (BQDS, $97 \%$, Sigma-Aldrich) in $1 \mathrm{M}$ sulphuric acid utilising ultrapure water from a Millipore Milli-Q water purification system $(<18.2$ $\mathrm{M} \Omega \mathrm{cm})$.

The solubility of BQDS (white powder at room temperature and pressure) was determined by a gravimetric method upon dissolving a known quantity of the electrolyte in a known quantity of sulfuric acid. Once precipitation was observed, the solubility was noted.

Rotating Disk Electrode (RDE) techniques were performed using a mirror polished glassy carbon disk electrode (Pine Instruments, AFE6R1 AU) with a $5 \mathrm{~mm}$ diameter equipped with a rotator (AFMSRCE). Electrochemical tests were performed using a potentiostat (Autolab, model PGSTAT20) and a custommade three compartment electrochemical glass cell which employed a Pt wire counter electrode. A saturated calomel reference electrode (SCE, $E^{0}=0.244 \mathrm{~V} v$ s. SHE at $25^{\circ} \mathrm{C}$ ) was used as the reference electrode, which was ionically connected to the main compartment of the electrochemical glass cell via a Luggin capillary. Cyclic voltammetry (CV) and linear-sweep voltammetry (LSV) experiments were performed with a $1 \mathrm{mM}$ BQDS solution in a $1 \mathrm{M} \mathrm{H}_{2} \mathrm{SO}_{4}$ electrolyte. The rotation rates were from $500 \mathrm{rpm}$ to $3000 \mathrm{rpm}$. The CV scan rates were from $10 \mathrm{mV} \mathrm{s}^{-1}$ to $200 \mathrm{mV} \mathrm{s}^{-1}$. The LSV scan rate was $5 \mathrm{mV} \mathrm{s}^{-1}$.

${ }^{1} \mathrm{H}$ and ${ }^{13} \mathrm{C}$ NMR spectra were recorded using a Bruker Advance III HD $800 \mathrm{MHz}$ or $600 \mathrm{MHz}$ spectrometer equipped with triple-resonance cryoprobes. All spectrometers were controlled using Linux computers running Bruker Topspin 3 software. Chemical shifts were reported as $\delta$ values. Samples were prepared directly from the electrolyte without any dilution. The reference solvent $\left(\mathrm{D}_{2} \mathrm{O}\right)$ was enclosed in a capillary tube and placed into the NMR tube.

Electrochemical Impedance Spectroscopy (EIS) measurements were conducted for full RFCs at OCV using a $10 \mathrm{mV}_{\mathrm{p}-\mathrm{p}}$ sine amplitude from $0.3 \mathrm{~Hz}$ to $10 \mathrm{kHz}$ using a Gamry (reference 3000 , potentiostat mode). It is usually not possible to go beyond $10 \mathrm{kHz}$ in full RFCs and obtain reasonable results due to inductance of the test fixtures and cables.

The electrolyte was passed through the RFC 15 min before the measurement to infiltrate the graphite felt electrode and stabilize the electrolyte interface for the electrochemical reaction. The high frequency resistance at $10 \mathrm{kHz}$ was also measured from the discharge polarization curves at various current densities. Open circuit potential (OCP) measurements were conducted before the charge and discharge test in potentiostatic mode. 


\section{Results and discussion}

RFB performance is a function of ohmic losses, charge transfer resistance and mass transport polarisation overpotential. In this context, charge transfer resistance is not just proportional to the number of electrons exchanged at the electrode-electrolyte interface but also a function of the activation losses due to the reaction. In contrast, since an RFB is operated under forced convection, mass transport polarisation is associated with inhomogeneous distribution of the electrolyte within the electrode. This means that the diffusion of the active species from the electrolyte interface to the active surface on the electrode has a strong influence on the performance of the battery. ${ }^{50}$ Therefore, calculation of both electron transfer and diffusion coefficients are significant figures of merit that inform the potential of the redox reaction as a candidate for RFB applications. In this regard, the determination of such figures of merit warrant their evaluation by means of important electrochemical characterisation techniques such as CV, RDE, LSV and others. ${ }^{51}$

Firstly the limiting solubility of BQDS was determined to be $0.65 \mathrm{M}$, which enables higher theoretical energy density than that of the hydroquinone system $(0.5 \mathrm{M}) .{ }^{39}$ Secondly its standard electrochemical potential ( $0.86 \mathrm{~V} v s$. SHE) was determined from $\mathrm{CV}$ experiments and found to be higher than that of the (ferrocenylmethyl)trimethylammonium chloride (Fe-NCL) system
(0.67 V vs. SHE). ${ }^{27}$ Hydroquinone $^{39}$ also has an identical potential to Fe-NCL but the solubility of the latter was higher (4 M).

In addition, to obtain further information on the kinetics of the BQDS electron transfer process on glassy carbon electrodes, cathodic and anodic voltammetric experiments were performed with a rotating-disk electrode using a solution of $1 \mathrm{mM}$ BQDS in $1 \mathrm{M} \mathrm{H}_{2} \mathrm{SO}_{4}$. It can be seen from Fig. 1A that the magnitude of anodic polarization currents increases with electrode rotation speed and as the potential is raised, a current plateau appears in the polarization curve around $1.4 \mathrm{vs}$. SHE at electrode rotation speeds between 500 and $3000 \mathrm{rpm}$, exhibiting characteristics of the limiting current indicative of mass-transfer control for the electrode process of BQDS oxidation.

When the disk-electrode reactions were completely controlled by mass-transport, the diffusion coefficient of BQDS was determined from the Levich equation. ${ }^{52}$ This analysis was performed by plotting the anodic limiting current density against the square root of angular speed as shown in Fig. 1B to determine the diffusion coefficient of BQDS to be $5.1 \times 10^{-6}$ $\mathrm{cm}^{2} \mathrm{~s}^{-1}$ (determined from the slope of the straight line in Fig. 1B). In comparison to other organic-based species in aqueous environments $\left(5.03 \times 10^{-6}\right.$ for hydroquinone and 3.74 $\times 10^{-6} \mathrm{~cm}^{2} \mathrm{~s}^{-1}$ for Fe-NCL) BQDS has a higher diffusion coefficient. However, the BQDS species has a slightly slower
(A)

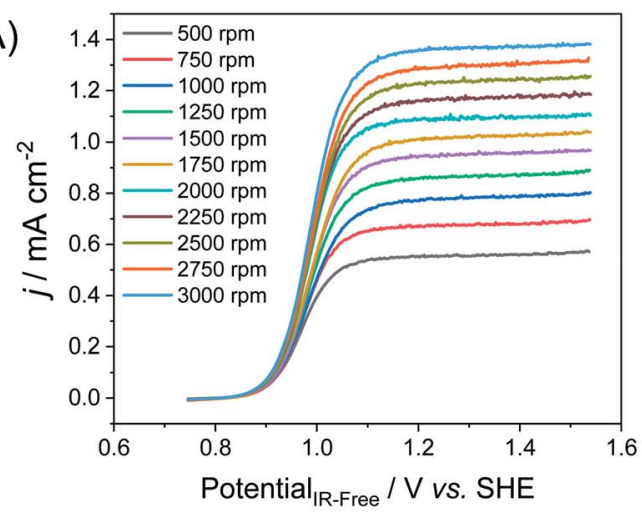

(C)

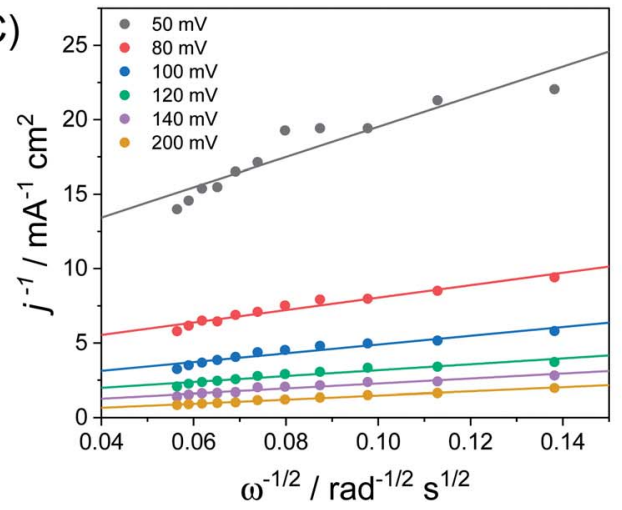

(B)

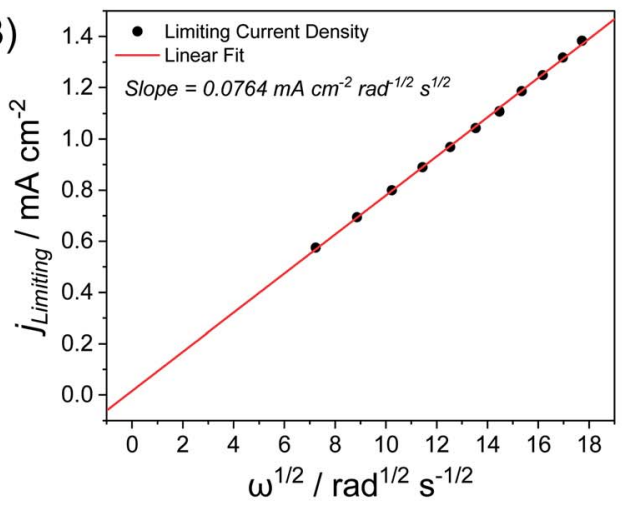

(D)

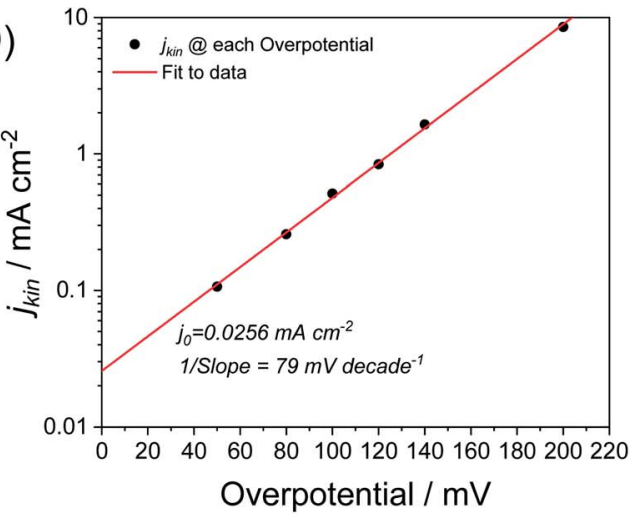

Fig. 1 (A) Linear-sweep voltammetry at a scan rate of $5 \mathrm{mV} \mathrm{s}^{-1}$ with the RDE (glassy carbon) in freshly prepared $1 \mathrm{M} \mathrm{H}_{2} \mathrm{SO}_{4} \mathrm{containing} 1 \mathrm{mM}$ BQDS. The rotation rate increased from 500 to $3000 \mathrm{rpm}$. (B) Levich plot of the square root of rotation rate vs. the limiting current for BQDS. (C) Koutecký-Levich plot for different overpotentials. (D) Tafel logarithmic plot of overpotential vs. kinetic current density. 
diffusion coefficient than vanadium (diffusion coefficient of $\mathrm{VO}^{2+}$ at $\left.20{ }^{\circ} \mathrm{C}=5.63 \times 10^{-6} \mathrm{~cm}^{2} \mathrm{~s}^{-1}\right) .{ }^{53}$ In addition, the electrochemical potentials of vanadium (1.01 V vs. SHE) and TEMPO (0.90 V vs. SHE) are higher.

From the Koutecký-Levich plot as displayed in Fig. 1C (for a freshly prepared electrolyte), it can be observed that for the set of current densities sampled at different overpotentials their intercepts on the vertical axis (corresponding to an infinite rotation rate) are non-zero. This indicates that the kinetics of electron transfer for BQDS on glassy carbon is slow. To further confirm this, a Tafel plot is generated as shown in Fig. 1D. In this regard, the exchange current density, $i_{0}$, and transfer coefficient, $\alpha$, are determined from the intercept and slope of the Tafel plot, respectively. ${ }^{52}$ As expected, the charge transfer coefficient of BQDS (0.38) was lower than that of hydroquinone (0.51) suggesting that the oxidation of BQDS suffers from an asymmetric barrier. A low exchange current density, $j_{0}=0.026$ $\mathrm{mA} \mathrm{cm}{ }^{-2}$, also confirms the same. Literature values at a similar concentration for other couples show that BQDS has moderate kinetics. For instance the $\mathrm{Fe}^{2+} / \mathrm{Fe}^{3+}$ couple has $j_{0}=3.2 \mathrm{~mA}$ $\mathrm{cm}^{-2},{ }^{54}$ which is higher than that of BQDS whereas $j_{0}$ for the quinone/hydroquinone couple $\mathrm{e}^{55}$ is significantly lower $(5.64 \times$ $10^{-6} \mathrm{~mA} \mathrm{~cm}^{-2}$ ) suggesting a reasonable kinetic performance of the BQDS system in comparison.

A high redox potential of the positive redox material will lead to a high cell voltage directly when coupled with the appropriate anolyte. Amongst the organic redox materials reported in the literature, the redox potential of BQDS is relatively high and this may mean that applying an electrode with a large surface area/ porosity in a high concentration of the electrolyte is expected to result in high current and power densities. As a consequence, we coupled this redox species with the hydrogen evolution/ oxidation reaction (HER/HOR) that is widely being studied in the literature ${ }^{15,17,56}$ for RFC applications.

The hybrid RFC single cell was assembled as described in the Experimental section and was tested under galvanostatic conditions at deep depths of discharge (DoD) unlike other organic systems that were only evaluated using a large number of shallow cycles. ${ }^{31}$ The RFB's major advantage is its ability to be operated reversibly at deep DoDs and its instantaneous response times. ${ }^{3}$ Tests utilizing shallow cycling operation do not represent a figure of merit appropriate for evaluating RFB technology suitably and in this work, we aimed at delivering a representative performance metric for the $\mathrm{H}_{2}$ /BQDS system.

The fully assembled $\mathrm{H}_{2}$ /BQDS RFC was evaluated against several figures of merit such as polarisation curves that were determined at different states-of-charge (SoC), as shown in Fig. 2A. This allows us to establish the peak power density for the system and visualise performance limitations. As expected, the RFC can be operated at higher power densities at $100 \%$ SoC $\left(122 \mathrm{~mW} \mathrm{~cm}^{-2}\right.$ at $\left.0.32 \mathrm{~V}\right)$ when compared to liquid electrolytes at a lower SoC $\left(70 \mathrm{~mW} \mathrm{~cm}^{-2}\right.$ at $0.27 \mathrm{~V}$ and $50 \mathrm{~mW} \mathrm{~cm}^{-2}$ at $0.24 \mathrm{~V}$ for $75 \%$ and $50 \%$ SoC, respectively).

Nonetheless this peak power is significantly lower in comparison to those of the RHVFC and $\mathrm{Mn} / \mathrm{H}_{2}$ RFC systems reported in the literature. ${ }^{\mathbf{1 5 , 1 8}}$ In these plots the ohmic resistance of the cell was compensated for using the high frequency resistance values measured at each current density (Fig. 2A, inset) and this led to an $i R$-free polarisation curve for our $\mathrm{H}_{2} /$ BQDS RFC, which appeared to be limited by the reaction kinetics of BQDS.

As a result, we investigated the effect of temperature on the reaction kinetics and battery performance. Interestingly the peak power at $60{ }^{\circ} \mathrm{C}$ (Fig. 2B) doubles compared to that at room temperature as it goes beyond $140 \mathrm{~mW} \mathrm{~cm}^{-2}$ at $0.33 \mathrm{~V}$ even at relatively low SoC $(75 \%)$. It is worth mentioning that operating the vanadium or manganese-based chemistries at such high temperatures is likely to cause precipitation of the active species thereby reducing cell performance, indicating another useful advantage of the BQDS electrolyte. However, as indicated by a leading flow battery group in Dalian, the peak power density is not an adequate figure of merit to determine the performance of a flow battery. ${ }^{13}$ This is due to the high battery cost linked to the electrolyte and the necessity of reaching high electrolyte utilization $(>85 \%)$ and round-trip efficiency which decreases as the operating current density increases. As a result, we decided to evaluate our RFC chemistry with regard to its round-trip efficiency and electrolyte utilisation at different charge/discharge current densities and simultaneously observe cell performance under deep charge/discharge cycling conditions.

In Fig. $2 \mathrm{C}$ the $\mathrm{H}_{2}$ /BQDS RFC is allowed to undergo galvanostatic charge/discharge at current densities ranging from 40 to $100 \mathrm{~mA} \mathrm{~cm}{ }^{-2}$. It is worth mentioning that the initial battery charge utilizing fresh liquid electrolytes requires at least 2.5 times higher capacity for a 2-electron transfer reaction in order to be fully charged. However, subsequent battery cycles present coulombic efficiencies above $90 \%$ for all studied current densities. This indicates that, although battery operation may change the nature of the redox couple, the resulting redox species offer good reversibility. This phenomenon is further investigated in the following sections.

The energy efficiency of $67 \%$ at $100 \mathrm{~mA} \mathrm{~cm}^{-2}$ is significantly better than that of most other organic RFB systems that operate normally at $50 \mathrm{~mA} \mathrm{~cm}^{-2}$ or even at lower current densities. ${ }^{32,39,57}$ In general, the cell has a better performance at low current densities with respect to the utilization and the consumption of the redox active material, which is expected. However, the battery output power will be low when it is operated at low current densities. Hence, the RFC is cycled at $100 \mathrm{~mA} \mathrm{~cm}{ }^{-2}$ about 200 times and its efficiency for each cycle number is displayed in Fig. 2D. Due to evaporation of water into the hydrogen gas stream during cycling, the electrolyte volume is topped-up with pure water around cycles 25, 75 and 175 as displayed by the spikes in both voltaic and energy efficiencies in Fig. 2D. In an operational system, water lost to the hydrogen stream would be recovered and added back into the electrolyte, although we have not done this.

During the cycling experiments (Fig. 2D), the cell achieved an average current efficiency of $95 \%$ and an average energy efficiency of $61 \%$. The maximum charge capacity and energy density were $13.98 \mathrm{~A} \mathrm{~h} \mathrm{~L}^{-1}$ and $10.90 \mathrm{~W} \mathrm{~h} \mathrm{~L}^{-1}$ respectively. This performance is comparable to that of a commercially available all-vanadium RFB which normally operates below $120 \mathrm{~mA} \mathrm{~cm}^{-2}$ 


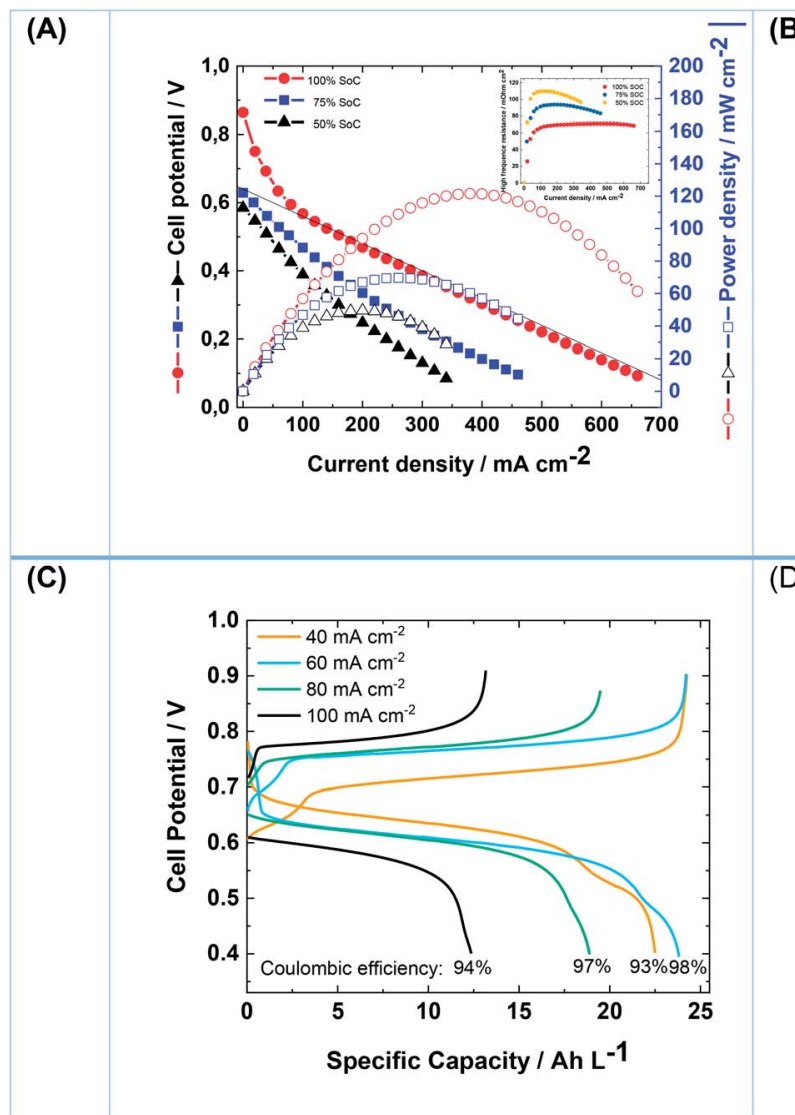

(B)

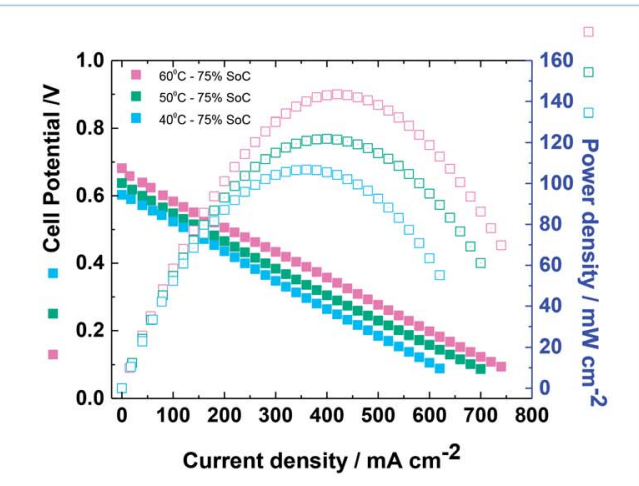

(D)

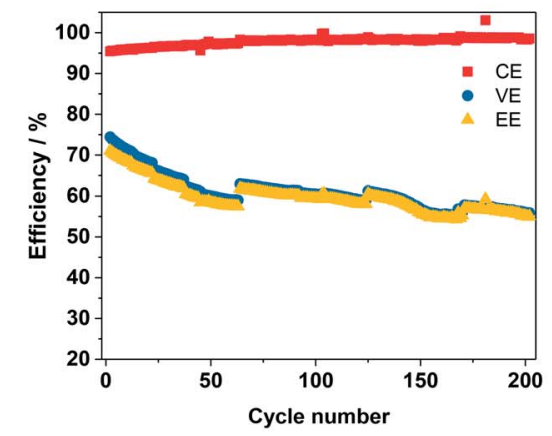

Fig. 2 (A) Polarization curves of $\mathrm{BQDS} / \mathrm{H}_{2} \mathrm{RFC}$ with $0.65 \mathrm{M} \mathrm{BQDS}$ in a $1 \mathrm{M} \mathrm{H}_{2} \mathrm{SO}_{4}$ solution at $50 \%$, $75 \%$, and $100 \%$ SoC. The inset shows the resistance of the $\mathrm{BQDS} / \mathrm{H}_{2} \mathrm{RFC}$ as a function of the discharge current density. $2.6 \mathrm{~mm}$ carbon felt was used for the BQDS half-cell. (B) Polarization curves of the BQDS/ $\mathrm{H}_{2} \mathrm{RFC}$ with $0.65 \mathrm{M} \mathrm{BQDS}$ in a $1 \mathrm{M} \mathrm{H}_{2} \mathrm{SO}_{4}$ solution, $\mathrm{SoC}=75 \%, \mathrm{~T}=40{ }^{\circ} \mathrm{C}, 50^{\circ} \mathrm{C}, 60^{\circ} \mathrm{C}$. (C) $\mathrm{Charge}$ and discharge curves of a $0.65 \mathrm{M}$ BQDS/hydrogen RFC. $2.6 \mathrm{~mm}$ carbon felt was used for the BQDS half-cell. (D) Cycling efficiency vs. cycle number. CE = coulombic, $\mathrm{VE}=$ voltaic and $\mathrm{EE}=$ energy efficiencies at a constant charge/discharge current density of $100 \mathrm{~mA} \mathrm{~cm}^{-2}$. BQDS total electrolyte volume $=200 \mathrm{~mL}$. The RFC used a $4.6 \mathrm{~mm}$ carbon felt for the BQDS half-cell. All graphs were produced using a $200 \mathrm{~mL}$ BQDS liquid electrolyte

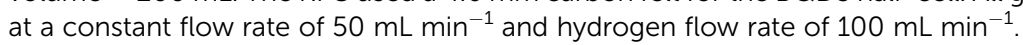

(commonly $80 \mathrm{~mA} \mathrm{~cm}{ }^{-2}$ ) to ensure high energy efficiency $(\approx 85 \%)$ and good electrolyte utilization $(>75 \%){ }^{\mathbf{1 3 , 1 5}}$ The charge and discharge cycling data may also be favourably compared with organic RFB systems discussed in the literature..$^{32,39,57}$ As per Yang and co-workers, the key factors governing the operation of an organic RFB are charge transfer and mass transport processes, operating cell voltage, faradaic efficiency, reactivity and long term cycling. ${ }^{39}$ In general, the low voltage, the low energy density, and the short lifetime are the primary challenges for the RFB system applying organic redox couples. In this aspect, the performance of our $\mathrm{H}_{2}$ /BQDS system surpasses the performance of other aqueous-organic systems reported in the literature. ${ }^{39}$ It needs to be mentioned that, in order to overcome the issues associated with water evaporation over long term cycling, water was added every $40-60$ cycles. This has an influence on the viscosity at the liquid side, and an improvement in VE and EE is observed (Fig. 2D). In a large-scale system based on this technology, water evaporated into hydrogen during charging would be recovered before storage and fed back into the liquid electrolyte. Hence the issue of water evaporation is unlikely to lead to operational problems.
The $\mathrm{H}_{2} / \mathrm{BQDS}$ is comparable in terms of cell voltage and energy density to the AQDS/Br ${ }_{2}$ system. Furthermore, our cell architecture offers an additional benefit associated with easy management of active species which have crossed over the membrane. This process leads to irreversible degeneration in the case of the $\mathrm{AQDS} / \mathrm{Br}_{2}$ flow battery, ${ }^{23}$ but in our system it is easily managed by pumping any crossover liquid back into the BQDS electrolyte tank. For this reason, our system maintains good faradaic efficiencies over 200 cycles with minimal capacity losses. In comparison to other organic couples tested in flow systems, our system outperforms them all in terms of important figures of merit such as energy and current densities but shows poorer cell voltage in comparison to $\mathrm{PbSO}_{4} / \mathrm{BQDS}$ and $\mathrm{MV} / 4$ HO-TEMPO. ${ }^{57}$ Hence, our system is durable and is worthy of consideration for practical scaling-up opportunities despite suffering from a somewhat low practical cell voltage.

We decided to investigate the origin of the gradual energy efficiency decrease observed for a full cell in Fig. 2D using CV in a 3-electrode cell configuration for a pure BQDS electrolyte and compare the data with the CV curves obtained for an electrolyte after operating the battery for 200 cycles. From the CV curve of pure BQDS in Fig. 3A, $\left(E_{\mathrm{p}, \mathrm{a}}+E_{\mathrm{p}, \mathrm{c}}\right) / 2$ yields a redox potential of 
(A)

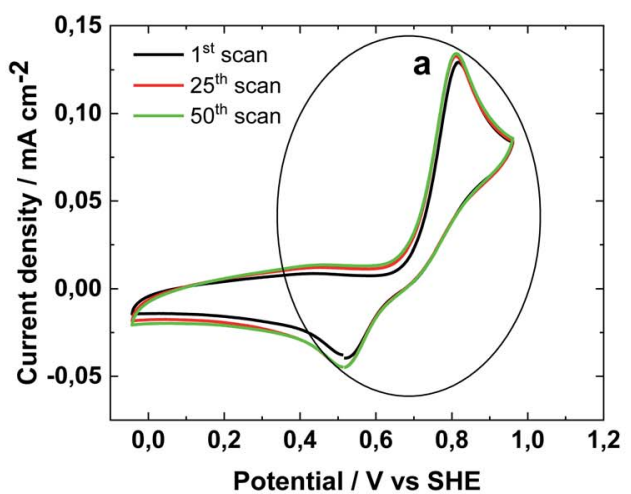

(C)

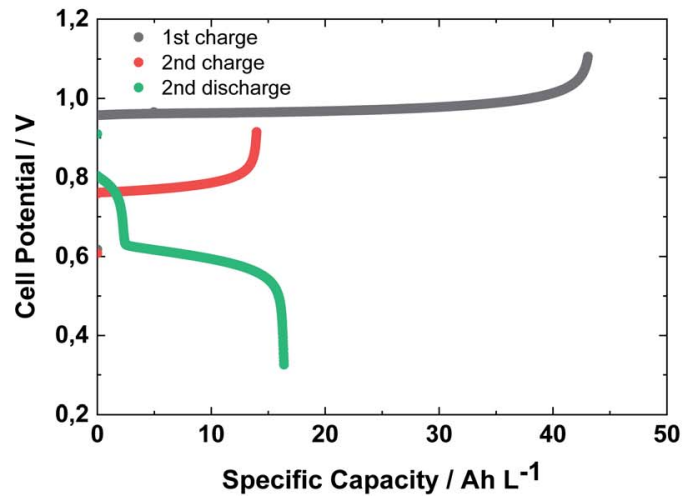

(B)

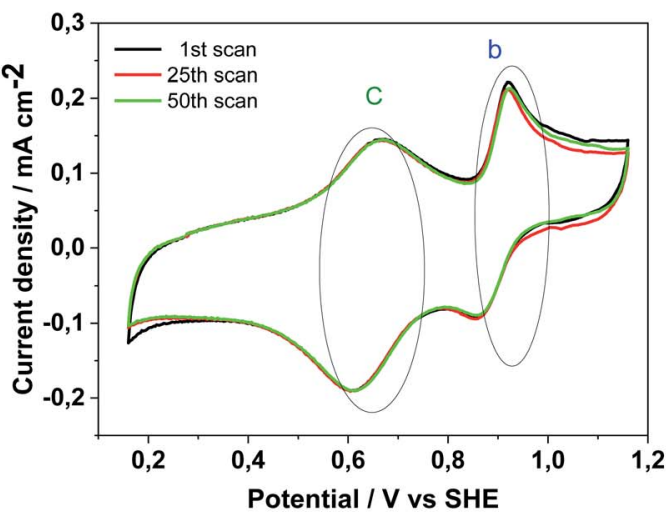

(D)
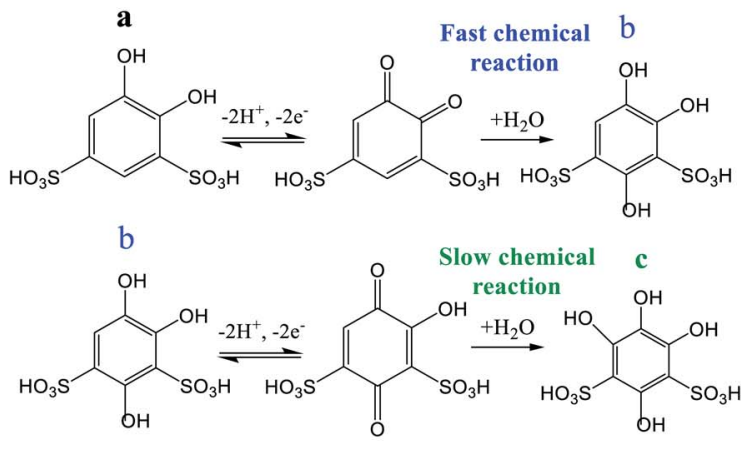

Fig. 3 (A) Cyclic voltammetry at a scan rate of $10 \mathrm{mV} \mathrm{s}^{-1}$ in a three-electrode cell. The electrolyte is freshly prepared $1 \mathrm{mM} B Q D S$ in $1 \mathrm{M} \mathrm{H}_{2} \mathrm{SO}_{4}$. $E_{\mathrm{p}, \mathrm{a}}=1.0 \mathrm{~V}, \mathrm{~J}_{\mathrm{p}, \mathrm{a}}=0.30 \mathrm{~mA} \mathrm{~cm}{ }^{-2}, E_{\mathrm{p}, \mathrm{c}}=0.72 \mathrm{~V}, \mathrm{~J}_{\mathrm{p}, \mathrm{c}}=-0.12 \mathrm{~mA} \mathrm{~cm}{ }^{-2}$, and $\Delta E_{\mathrm{l}}=0.28 \mathrm{~V}$. (B) Cyclic voltammetry at a scan rate of $10 \mathrm{mV} \mathrm{s}^{-1}$ in a three-electrode cell. The electrolyte is $1 \mathrm{mM} \mathrm{BQDS}$ obtained upon dilution of the RFC electrolyte after operating for 200 full charge/discharge cycles (solution diluted with $1 \mathrm{M} \mathrm{H}_{2} \mathrm{SO}_{4}$ ). (C) Charge and discharge curve of a $0.65 \mathrm{M} \mathrm{BQDS/hydrogen} \mathrm{RFC}$ at a constant charge/discharge current density of $100 \mathrm{~mA} \mathrm{~cm}^{-2}$. BQDS total electrolyte volume $=20 \mathrm{~mL}$ liquid electrolyte at a constant flow rate of $50 \mathrm{~mL} \mathrm{~min}^{-1}$ and hydrogen flow rate of $100 \mathrm{~mL} \mathrm{~min}{ }^{-1}$. (D) Proposed mechanism for the hydroxylation of BQDS upon interpretation of $\mathrm{CV}$ data.

$0.86 \mathrm{~V}$. The BQDS undergoes a very fast oxidation reaction even though no catalyst was used on the glassy carbon surface during the CV scan. Due to the acidic conditions, the electron transfer of quinone-based substances is a concerted process and no radical intermediate is formed. ${ }^{39}$ The ratio of the slope between anodic and cathodic peaks is greater than one, suggesting that the BQDS oxidation is faster than the reduction. This is in contradiction with the transfer coefficient which was determined from the Tafel plot in Fig. 1D $(\alpha=0.34)$ which implied that the reduction of BQDS would be more facile than the oxidation. However, it needs to be observed that the reversibility of the reaction shown in the $\mathrm{CV}$ curves measured as the separation between anodic and cathodic peaks is $0.28 \mathrm{~V}$, which is significantly larger than that of the theoretical value of the reversible reaction $(0.059 / n \mathrm{~V})$. It is anticipated that the electrode kinetics and thus the charge transfer coefficient of BQDS may be improved in future investigations by performing thermal pre-treatment or modifying the electrodes with carbon nano-tubes and/or graphene., ${ }^{9,17,18,45}$

As a result, the conjunction of moderate reduction kinetics and poor reversibility for fresh BQDS may be explained as the result of electrochemical oxidation which would occur followed by a chemical reaction (EC mechanism). In this context, the reduction wave with a peak at around $0.52 \mathrm{~V}$ would be associated with a redox couple with a modified structured when compared to fresh BQDS. This explanation would be in good alignment with the reaction of BQDS with 2,4,5trihydroxybenzene-1,3-disulfonic acid via the Michael addition reaction which was detected by NMR spectroscopy (see the ESI $†$ ) and has been suggested by Yang $e t$ al. to explain the degradation of their liquid-liquid RFB. ${ }^{39,40}$

The chemical modification of the BQDS with $\mathrm{OH}$ groups leads to species with a lower redox potential than that of the pristine one. This would explain the gradual decrease in cell voltage and the observed decrease in VE and EE observed in our $\mathrm{H}_{2}$-BQDS system as well as the first battery charge which involves 2-3 times higher charge than expected for a 2-electron process (Fig. 3C). This would also explain the large difference in Open Circuit Voltage (OCV) observed at different SoC in Fig. 2A which cannot be simply attributed to electrolyte composition and concentration of the species as described by the Nernst equation but would also be associated with the formation of new species with lower redox potential. 
Our study suggests that the first hydroxylation is a very fast reaction process which occurs subsequent to the electrochemical oxidation (see Fig. 3D). This is supported by the CV curves for a freshly prepared electrolyte (Fig. 3A). The trihydroxy compound $\mathbf{b}$ would offer similar redox potential to that of the dihydroxy compound a but with a lower $\Delta E$ which means better reversibility. Moreover, b would present higher chemical stability than a, and the formation of the fully substituted quinone $\mathbf{c}$ which is validated by the redox wave found at $0.65 \mathrm{~V}$ in Fig. 3B is a significantly slower chemical process as it was not completed after 200 battery cycles.

Future work to ensure sustained performance of the $\mathrm{H}_{2}$-BQ RFC may be linked to the isolation of specific BQ structures with high redox potential and enhanced chemical stability such as the one suggested by Yang et al. ${ }^{39,40}$ In this respect, a group at Harvard conducted computational simulation to identify over 300 quinones for organic flow battery applications. ${ }^{25}$ The selection of some of these feasible quinones could pave the way to a high-performance $\mathrm{H}_{2}$-quinone $\mathrm{RFC}$, which is predicted to vastly reduce the cost of electrical energy storage. This is because the $\mathrm{H}_{2}$ /quinone RFC combines the advantage of the high stability of quinones at high potentials and the facile means of handling electrolyte crossover from the hydrogen-side half-cell. Further work is expected to test several combinations of such redox couples in terms of experimental and modelling investigations to reveal potential commercialisation routes.

\section{Conclusions}

The electrochemical properties of the organic redox material BQDS are investigated in this work including the redox potential, the diffusion coefficient, the rate constant and the charge transfer coefficient. By using an organic redox material with low cost in tandem with an abundant hydrogen source, a novel regenerative fuel cell was successfully developed. Using $0.65 \mathrm{M}$ BQDS in $1 \mathrm{M}$ sulphuric acid on the positive side and gaseous hydrogen on the negative side, the RFC system was able to run at $100 \mathrm{~mA} \mathrm{~cm}{ }^{-2}$ for 200 cycles maintaining over $95 \%$ current efficiency and delivered a power density of $122 \mathrm{~mW} \mathrm{~cm}^{-2}$ at room temperature. At a current density of $40 \mathrm{~mA} \mathrm{~cm}^{-2}$, the cell achieved a capacity of $23.8 \mathrm{~A} \mathrm{~h} \mathrm{~L}^{-1}$ with a redox material utilization of $82 \%$. This research proved that the combination of organic materials and hydrogen is a practical redox couple for an RFC system. The BQDS/hydrogen RFC has a comparable performance with some typical organic RFB systems reported in the literature, but at the same time, it has similar issues such as low energy density and limited cycle lifetime. In addition, compared with the commercialised VRFB system, the power density of this RFC still needs to be improved prior to exploiting potential scaling-up opportunities in future.

\section{Conflicts of interest}

A UK patent application has been filed on this specific technology.

\section{Acknowledgements}

The authors would like to acknowledge support from the Engineering and Physical Sciences Research Council under projects EP/L014289/1, EP/P003494/1, EP/N032888/1 and EP/ R023581/1. We would like to thank Dr Andres Parra-Puerto for his help in obtaining some of the experimental plots. The data used in the creation of the plots in this article are available to download at Zenodo (DOI: 10.5281/zenodo.3627983).

\section{References}

1 P. Leung, X. Li, C. Ponce de León, L. Berlouis, C. T. J. Low and F. C. Walsh, RSC Adv., 2012, 2, 10125.

2 M. H. Chakrabarti, S. A. Hajimolana, F. S. Mjalli, M. Saleem and I. Mustafa, Arabian J. Sci. Eng., 2013, 38, 723-739.

3 M. Skyllas-Kazacos, M. H. Chakrabarti, S. A. Hajimolana, F. S. Mjalli and M. Saleem, J. Electrochem. Soc., 2011, 158, R55-R79.

4 M. H. Chakrabarti, N. P. Brandon, S. A. Hajimolana, F. Tariq, V. Yufit, M. A. Hashim, M. A. Hussain, C. T. J. Low and P. V. Aravind, J. Power Sources, 2014, 253, 150-166.

5 C. L. Chen, H. K. Yeoh and M. H. Chakrabarti, ECS Trans., 2015, 66, 1-23.

6 F. Tariq, J. Rubio-Garcia, V. Yufit, A. Bertei, B. Chakrabarti, A. Kucernak and N. Brandon, Sustainable Energy Fuels, 2018, 2, 2068-2080.

7 E. C. Knehr, K. W. Agar, E. Dennison, C. R. Kalidindi and A. R. Kumbur, J. Electrochem. Soc., 2012, 159, A1446-A1459.

8 K. W. Knehr and E. C. Kumbur, Electrochem. Commun., 2012, 23, 76-79.

9 B. K. Chakrabarti, V. Yufit, P. V. Aravind and N. P. Brandon, Int. J. Chem. Biomol. Eng., 2017, 11, 622-626.

10 C. Flox, M. Skoumal, J. Rubio-Garcia, T. Andreu and J. R. Morante, Appl. Energy, 2013, 109, 344-351.

11 R. M. Darling, K. G. Gallagher, J. A. Kowalski, S. Ha and F. R. Brushett, Energy Environ. Sci., 2014, 7, 3459-3477.

12 Y. Ashraf Gandomi, D. S. Aaron and M. M. Mench, Electrochim. Acta, 2016, 218, 174-190.

13 Q. Zheng, F. Xing, X. Li, T. Liu, Q. Lai, G. Ning and H. Zhang, Investigation on the performance evaluation method of flow batteries, J. Power Sources, 2014, 266, 145-149.

14 S. Kim, J. Yan, B. Schwenzer, J. Zhang, L. Li, J. Liu, Z. Yang and M. a. Hickner, Electrochem. Commun., 2010, 12, 16501653.

15 J. Rubio-Garcia, A. Kucernak, D. Zhao, D. Li, K. Fahy, V. Yufit, N. Brandon and M. Gomez-Gonzalez, Journal of Physics: Energy, 2018, 1, 015006.

16 V. Yufit, B. Hale, M. Matian, P. Mazur and N. P. Brandon, J. Electrochem. Soc., 2013, 160, A856-A861.

17 R. P. Dowd, V. S. Lakhanpal and T. Van Nguyen, J. Electrochem. Soc., 2017, 164, F564-F567.

18 K. M. Tenny, V. S. Lakhanpal, R. P. Dowd, V. Yarlagadda and T. Van Nguyen, J. Electrochem. Soc., 2017, 164, A2534-A2538.

19 J. Noack, C. Cremers, D. Bayer, J. Tübke and K. Pinkwart, J. Power Sources, 2014, 253, 397-403. 
20 X. Wei, W. Pan, W. Duan, A. Hollas, Z. Yang, B. Li, Z. Nie, J. Liu, D. Reed, W. Wang and V. Sprenkle, ACS Energy Lett., 2017, 2, 2187-2204.

21 A. Poullikkas, Renewable Sustainable Energy Rev., 2013, 27, 778-788.

22 Y. Xu, Y. Wen, J. Cheng, G. Cao and Y. Yang, Electrochem. Commun., 2009, 11, 1422-1424.

23 B. Huskinson, M. P. Marshak, C. Suh, S. Er, M. R. Gerhardt, C. J. Galvin, X. Chen, A. Aspuru-Guzik, R. G. Gordon and M. J. Aziz, Nature, 2014, 505, 195-198.

24 M. R. Gerhardt, L. Tong, R. Gómez-Bombarelli, Q. Chen, M. P. Marshak, C. J. Galvin, A. Aspuru-Guzik, R. G. Gordon and M. J. Aziz, Adv. Energy Mater., 2017, 7, 1601488.

25 S. Er, C. Suh, M. P. Marshak and A. Aspuru-Guzik, Chem. Sci., 2015, 6, 845-1592.

26 P. Leung, A. A. Shah, L. Sanz, C. Flox, J. R. Morante, Q. Xu, M. R. Mohamed, C. Ponce de León and F. C. Walsh, J. Power Sources, 2017, 360, 243-283.

27 B. Hu, C. Debruler, Z. Rhodes and T. L. Liu, J. Am. Chem. Soc., 2017, 139, 1207-1214.

28 B. Hwang, M. S. Park and K. Kim, ChemSusChem, 2015, 8, 310-314.

29 Y. Xu, Y. Wen, J. Cheng, Y. Yanga, Z. Xie and G. Cao, WNWEC 2009 - 2009 World Non-Grid-Connected Wind Power Energy Conf., 2009, pp. 475-478.

30 S. D. Pineda Flores, G. C. Martin-Noble, R. L. Phillips and J. Schrier, J. Phys. Chem. C, 2015, 119, 21800-21809.

31 T. Janoschka, N. Martin, U. Martin, C. Friebe, S. Morgenstern, H. Hiller, M. D. Hager and U. S. Schubert, Nature, 2015, 527, 78-81.

32 J. Winsberg, C. Stolze, A. Schwenke, S. Muench, M. D. Hager and U. S. Schubert, ACS Energy Lett., 2017, 2, 411-416.

33 K. Lin, Q. Chen, M. R. Gerhardt, L. Tong, S. B. Kim, L. Eisenach, A. W. Valle, D. Hardee, R. G. Gordon, M. J. Aziz and M. P. Marshak, Science, 2015, 349, 1529-1532.

34 D. G. Kwabi, K. Lin, Y. Ji, E. F. Kerr, M.-A. Goulet, D. De Porcellinis, D. P. Tabor, D. A. Pollack, A. Aspuru-Guzik, R. G. Gordon and M. J. Aziz, Joule, 2018, 2, 1894-1906.

35 T. J. Carney, S. J. Collins, J. S. Moore and F. R. Brushett, Chem. Mater., 2017, 29, 4801-4810.

36 Q. Chen, L. Eisenach and M. J. Aziz, J. Electrochem. Soc., 2016, 163, A5057-A5063.

37 J. M. Campos-Martin, G. Blanco-Brieva and J. L. G. Fierro, Angew. Chem., Int. Ed., 2006, 45, 6962-6984.

38 J. K. Edwards, B. Solsona, E. Ntainjua N, A. F. Carley, A. A. Herzing, C. J. Kiely and G. J. Hutchings, Science, 2009, 323, 1037-1041.

39 B. Yang, L. Hoober-Burkhardt, F. Wang, G. K. Surya Prakash and S. R. Narayanan, J. Electrochem. Soc., 2014, 161, A1371A1380.
40 B. Yang, L. Hoober-Burkhardt, S. Krishnamoorthy, A. Murali, G. K. S. Prakash and S. R. Narayanan, J. Electrochem. Soc., 2016, 163, A1442-A1449.

41 V. Yarlagadda, G. Lin, P. Y. Chong and T. Van Nguyen, J. Electrochem. Soc., 2016, 163, A5134-A5143.

42 Y. Li and T. Van Nguyen, J. Electrochem. Soc., 2018, 165, F1139-F1146.

$43 \mathrm{H}$. Kreutzer, V. Yarlagadda and T. Van Nguyen, J. Electrochem. Soc., 2012, 159, F331-F337.

44 C. A. P. Muñoz, H. H. Dewage, V. Yufit and N. P. Brandon, J. Electrochem. Soc., 2017, 164, F1717-F1732.

45 C. A. P. Muñoz, B. K. Chakrabarti, V. Yufit and N. P. Brandon, J. Electrochem. Soc., 2019, 166, A3511-A3524.

46 S. Nawar, B. Huskinson and M. J. Aziz, in Materials Research Society Symposium, 2013, p. 6.

47 N. Christudas Dargily, R. Thimmappa, Z. Manzoor Bhat, M. C. Devendrachari, A. R. Kottaichamy, M. Gautam, S. P. Shafi and M. O. Thotiyl, J. Phys. Chem. Lett., 2018, 9, 2492-2497.

48 G. Lin, P. Y. Chong, V. Yarlagadda, T. V. Nguyen, R. J. Wycisk, P. N. Pintauro, M. Bates, S. Mukerjee, M. C. Tuckere and A. Z. Weber, J. Electrochem. Soc., 2016, 163, A5049-A5056.

49 M. Ulaganathan, V. Aravindan, Q. Yan, S. Madhavi, M. Skyllas-Kazacos and T. M. Lim, Adv. Mater. Interfaces, 2016, 3, 1-22.

50 J. D. Milshtein, A. P. Kaur, M. D. Casselman, J. A. Kowalski, S. Modekrutti, P. L. Zhang, N. Harsha Attanayake, C. F. Elliott, S. R. Parkin, C. Risko, F. R. Brushett and S. A. Odom, Energy Environ. Sci., 2016, 9, 3531-3543.

51 Y. A. Gandomi, D. S. Aaron, J. R. Houser, M. C. Daugherty, J. T. Clement, A. M. Pezeshki, T. Y. Ertugrul, D. P. Moseley and M. M. Mench, J. Electrochem. Soc., 2018, 165, A970A1010.

52 Y.-H. Wen, H.-M. Zhang, P. Qian, H.-P. Ma, B.-L. Yi and Y.-S. Yang, Chin. J. Chem., 2007, 25, 278-283.

53 W. Wang, X. Fan, J. Liu, C. Yan and C. Zeng, RSC Adv., 2014, 4, 32405-32411.

54 T. Sawant and J. McKone, ChemRxiv, DOI: 10.26434/ chemrxiv.6203297.v1.

55 D. P. Bhatt, M. Anbuchezian, R. Balasubramanian, R. Udhayan and V. K. Venkatesan, J. Power Sources, 1993, 45, 177-186.

56 R. P. Dowd, A. Verma, Y. Li, D. Powers, R. Wycisk, P. N. Pintauro and T. Van Nguyen, J. Electrochem. Soc., 2017, 164, F1608-F1614.

57 T. Liu, X. Wei, Z. Nie, V. Sprenkle and W. Wang, Adv. Energy Mater., 2015, 6, 1501449. 